\section{Managing Expectations}

$\mathbf{W}$ Then I was in training many years ago, I struggled with the knowledge that most of my patients would succumb to their disease while I was also trying to partner with them to "get better" to whatever extent treatment would allow. I remember asking a beloved senior mentor what to say when my patient with metastatic pancreatic cancer tells me they hope they will be cured. She responded quickly and simply: You say, you hope so, too! That lesson has helped me over and over again throughout my career.

When we meet a new patient, we have a lot of teaching to do. What does the diagnosis mean? What are the goals of treatment? What treatments are available? What are the side effects? Is cure possible? If not cure, can we make this a chronic condition? The list goes on.

Often, a patient looks me in the eye and asks directly, "How long will I live?" They ask as though I have a crystal ball on my desk and that I'm a fortune teller. My answer is always the same: I don't know. I can tell a patient the average lifespan for a group with their disease and the range of possibilities. But, in fact, lifespan for any given patient depends on the outcome of treatment and perhaps a bit of luck.

Although I don't think we should ever sugarcoat a grave prognosis, I also don't think it's wise to steal hope away entirely. In fact, I think that can drive a patient to explore alternative therapies that often have no foundation and can actually be harmful. To be clear: I don't dismiss all alternative therapies, but many are promoted with outrageous claims and often come with a very high price tag.

And I teach trainees that you do need to be open to miracles. I follow several patients who have outcomes that you would not think possible. These patients with bona fide pancreatic cancer and biopsy-confirmed metastatic liver or distant nodal or lung disease are in complete remission for years. My record holder is 10 years at the moment. Did my treatment do this? Did some alternative practice that my patient didn't tell me about do this? Is it just a divine gift?

I'll never know.

The point is, it can happen. So when patients ask me if I have ever seen someone with their diagnosis survive, I can honestly say, yes. Not often, of course. But emphatically, yes.

The other point about hope is that a better treatment may be just around the corner. Over the years, we have seen new drugs or better treatment strategies emerge that made the impossible possible. A case in point is curative immunotherapy in metastatic melanoma. Although that might not have been such a stretch of the imagination, how about immunotherapy in metastatic lung cancer? Bet you never saw that coming!

So, I leave you with a parting thought. Sick or not, we should all have our affairs in order in case a calamity occurs. But if it does, remember this, too: It is okay to hope, even for a miracle. JNCCN@nccn.org or log into www.editorialmanager.com/JNCCN.

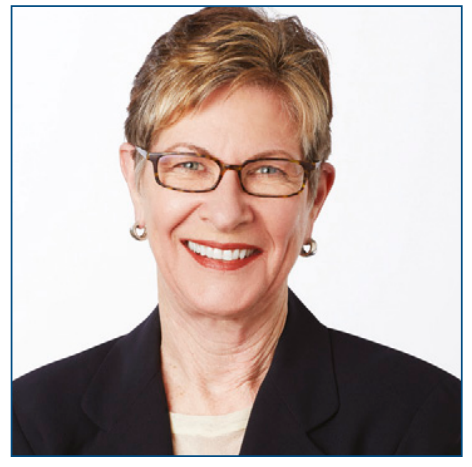

MARGARET TEMPERO, MD

Margaret Tempero, MD, is a Professor of Medicine and Director of the UCSF Pancreas Center and editor-in-chief of JNCCN. Her research career has focused on pancreatic ductal adenocarcinoma, especially in the area of investigational therapeutics. Dr. Tempero has served on the ASCO Board of Directors and as ASCO President. She currently serves on the ASCO Conquer Cancer Foundation Board. She codirected the AACR/ASCO Methods in Clinical Cancer Research and taught this course and similar courses in Europe and Australia. She was founding Chair of the $\mathrm{NCl}$ Clinical Oncology Study Section and served as a member and Chair of the $\mathrm{NCl}$ Board of Scientific Counselors Subcommittee A. She is a member of the Scientific Steering Committee and Chair of the Clinical and Translational Study Section for the Cancer Prevention \& Research Institute of Texas. She is or has been on the Scientific Advisory Boards of the Lustgarten Foundation, the Pancreatic Cancer Action Network, the V Foundation, The Alberta Canada Cancer Board, and the EORTC. She served as a member of the Oncology Drug Advisory Committee for the FDA. She has served as Deputy Director and Interim Director for the UNMC Eppley Cancer Center. She is Chief Emeritus of the Division of Medical Oncology at UCSF. She served as the founding Deputy Director and was later Director of Research Programs at the UCSF Helen Diller Family Comprehensive Cancer Center.

doi: $10.6004 /$ jnccn.2019.0040

The ideas and viewpoints expressed in this editorial are those of the author and do not necessarily represent any policy, position, or program of NCCN. 